\title{
Early hydration of ye'elimite: insights from thermodynamic modelling
}

\author{
Maciej Zajac ${ }^{1}$, Jan Skocek ${ }^{1}$, Frank Bullerjahn ${ }^{1}$, Barbara Lothenbach ${ }^{2}$, Karen Scrivener ${ }^{3}$, Mohsen Ben Haha ${ }^{1}$ \\ ${ }^{1}$ Global R\&D HeidelbergCement AG, Oberklamweg 2-4, 69181 Leimen, Germany \\ ${ }^{2}$ Empa, Swiss Federal Laboratories for Materials Science and Technology, Laboratory for \\ Concrete/Construction Chemistry, Überlandstrasse 129, 8600 Dübendorf, Switzerland \\ ${ }^{3}$ EPFL STI IMX LMC MXG 232 (Bâtiment MXG) Station 12 CH-1015 Lausanne Switzerland
}

1

\section{Abstract}

This study focuses on better understanding of early reaction of ye'elimite, the main constituent of calcium sulfoaluminate cements and the effect of minor phases.

Thermodynamic modelling was used to calculate the solubility in the tri-dimensional space of Ca-Al-S- $\mathrm{H}_{2} \mathrm{O}$ at different alkali concentrations and compared to changes in the pore solution concentrations during the ye'elimite reaction. It is demonstrated that the hydration pathways follow the stability fields of certain hydrates. The interplay between the solution properties and the solubility of different phases results in an increase of aluminium, sulfate, and calcium concentrations following the congruent dissolution of ye'elimite. Moreover, once hydrates start to precipitate, their supersaturation does not change as intensely as the pore solution concentration. This explains the slow reaction of pure ye'elimite. The same framework was applied to explain fast reaction of ye'elimite in the industrial clinkers and particularly the effect of $C_{12} A_{7}$ and alkalis.

Key words

A Hydration, A Reaction, B Thermodynamic Calculations, B Pore Solution, D Sulfoaluminate, E Modelling

\section{Introduction}

Ye'elimite phase is an important component of calcium sulfoaluminate (CSA) cements. CSA cement has been used in China as the "third cement series" for more than 30 years for construction and special applications [1] [2] and today, the production of CSA cement in China is more than 1 million tonnes per year [3]. Recently, belite-rich CSA cements, so-called belite ye'elimite ferrite (BYF) cements are gaining increasing attention of cement producers [4][5][6] as a low $\mathrm{CO}_{2}$ alternative to Portland cement. Despite the long history of the CSA systems use in many applications, the early hydration mechanisms of ye'elimite clinkers and/or cements are

This document is the accepted manuscript version of the following article:

Zajac, M., Skocek, J., Bullerjahn, F., Lothenbach, B., Scrivener, K., \& Ben Haha, M. (2019). Early hydration of ye'elimite: Insights from thermodynamic model1ing. Cement and concrete Research, 120, 152-163. https://doi.org/10.1016/j.cemconres.2019.03.024 
not well understood although the understanding of this mechanisms is very important since the hydration of ye'elimite regulates the evolution of the early cement performance [2] [7].

With water alone, the hydration of ye' elimite is often idealized according to the simple equation:

$$
1 C_{4} A_{3} \bar{S}+18 H \rightarrow 1 C_{4} A \bar{S} H_{12}+2 A H_{3} \text { Equation } 1
$$

to form monosulfate and aluminum hydroxide, with the latter being usually $\mathrm{X}$-ray amorphous. The addition of anhydrite modifies the reaction to:

$$
1 C_{4} A_{3} \bar{S}+2 C \bar{S}+38 H \rightarrow 1 C_{6} A \bar{S}_{3} H_{32}+2 A H_{3} \text { Equation } 2
$$

According to these reactions, the reaction products are monosulfate or ettringite and aluminium hydroxide in the final product. The content of ettringite and monosulfate is regulated by the ratio between ye'elimite and calcium sulfate. However, many publications [2] [8] [9][10] suggested that the reaction of ye' elimite with water is more complex than these simplified reactions as summarised in. The products of the synthetic ye'elimite reaction include a substantial amount of amorphous $\mathrm{CAH}_{10}$ phase and ettringite in addition to aluminium hydroxide and monosulfate [9][10]. The formation of $\mathrm{CAH}_{10}$ has also been observed in hydrated industrial clinkers and cements [11] [12] [13][14]. The $\mathrm{CAH}_{10}$ phase precipitation is closely linked to the nature of aluminium hydroxide. Aluminium hydroxide has three forms: XRD amorphous, microcrystalline phase or crystalline gibbsite [15] [16] [17]. These forms are characterized by different solubilities, amorphous aluminium hydroxide is the most soluble while gibbsite has the lowest solubility but it generally forms very slowly at room temperature [18]. During the early hydration, the amorphous form of aluminium hydroxide precipitates which stabilizes the $\mathrm{CAH}_{10}$ phase [11] [18] [8]. Later on, when microcrystalline aluminium hydroxide forms, the $\mathrm{CAH}_{10}$ phase is destabilized. Hence, even the hydration of the neat ye'elimite phase is more complex than the idealized reactions (1) and (2). Furthermore, the kinetics of the ye'elimite reaction vary strongly depending on the system investigated. Synthetic, pure ye'elimite reacts slowly [2][9] [19] while ye'elimite in industrial cements may react very rapidly [1] [8][20] [21] [22].

Despite considerable research on ye'limite / CSA hydration, there are few reported studies linking the pore solution properties with the evolution of the solid phases. Such studies are needed for understanding the early hydration mechanisms. Additionally, many of the studies focusing on early hydration investigated 
cement clinker or cements and using retarders [20] [23] [24], which may interfere with the hydration of the ye'elimite. Consequently, this hinders understanding the mechanisms of early reactions. Additionally, the earliest pore solution extractions reported are too late [20] [25] [26] [19] to capture all the early hydration features as these are typically gained only after few hours after the mixing with water.

The two main process that governs the hydration phenomena are dissolution and precipitation [28]. A suitable way to investigate the mechanisms of hydration is to compare the evolution of the pore solution composition resulting from the dissolution of anhydrous phases with the solubility surfaces of hydrates that may precipitate [28] [29]. In this paper, The GEM-Selektor software was applied to investigate the stability of hydrates in the Ca-Al-S-K- $\mathrm{H}_{2} \mathrm{O}$ system. The solubility surfaces for the main hydrates which may precipitate during the reaction of ye'elimite were calculated and compared them to the solution data to investigate the mechanisms of ye'elimite hydration, depending on the $\mathrm{Ca}, \mathrm{Al}, \mathrm{S}$ and alkali concentrations in the solution.

The thermodynamic modelling of the system Ca-Al-S- $\mathrm{H}_{2} \mathrm{O}$ and its sub-systems have been previously investigated by Damidot and Glasser using the state of the art databases available at that time [30] [31] [32]. However, the pore solution was treated in a simplified form without considering ion speciation. This is an important aspect since the measured data on the $\mathrm{Al}, \mathrm{Ca}$ and $\mathrm{S}$ concentration vary between $\mu \mathrm{M}$ and hundreds of $\mathrm{mM}$ during the hydration of ye'elimite. Additionally, the alkali concentration is typically limited to $0.1-1$ $\mathrm{mM}$ in the synthetic systems but can be hundreds of $\mathrm{mM}$ in the industrial cements [25]. The use of a modern geochemical software package, GEM-Selector, together with its standard database [33] [34] allows calculation of aqueous ion activities and speciation for the particular system studied. This thermodynamic database has been extended and updated considerably, as summarised in [11][18][35][36] allowing the stateof-the-art modelling.

In the present work, the starting point is the simple and relatively well known system Ca-Al- $\mathrm{H}_{2} \mathrm{O}$. It is analysed to explain the early hydration of calcium aluminate cements. In the next sections, more complex systems are presented including gradually the effect of alkalis and sulphate on the $\mathrm{Ca}-\mathrm{Al}-\mathrm{H}_{2} \mathrm{O}$ system. Finally, the Ca-Al-S$\mathrm{K}-\mathrm{H}_{2} \mathrm{O}$ system is discussed from the perspective of the reaction of the pure ye'elimite and ye'elimite in a 
cement clinker in order to consolidate our knowledge on the early hydration of the calcium sulfoaluminate phase.

\section{Materials and methods}

\subsection{Thermodynamic modelling}

Thermodynamic modelling was carried out using the geochemical modelling program GEM-Selector version 3.2 [37] [38] with thermodynamic data from the PSI-GEMS database [33] [34] supplemented by cement specific data from the CEMDATA18 database [35][36]. The database compiles thermodynamic data for hydrates such as ettringite, monosulfate and $\mathrm{CAH}_{10}$. The thermodynamic database includes also data for amorphous aluminium hydroxide $\left(\mathrm{Al}(\mathrm{OH})_{3}(\mathrm{am}), \log \mathrm{K}_{\mathrm{s} 0}=0.24\right.$ for the reaction $\mathrm{Al}(\mathrm{OH})_{3}(\mathrm{am})+\mathrm{OH}^{-} \Leftrightarrow \mathrm{Al}(\mathrm{OH})_{4}^{-}$ [18]), which has a higher solubility than microcrystalline aluminium hydroxide $\left(\mathrm{Al}(\mathrm{OH})_{3}(\mathrm{mic}), \log \mathrm{K}_{\mathrm{s} 0}=-0.67\right.$ for the reaction $\mathrm{Al}(\mathrm{OH})_{3}(\mathrm{mic})+\mathrm{OH}^{-} \Leftrightarrow \mathrm{Al}(\mathrm{OH})_{4}$; [35]. The CEMDATA18 database was completed with thermodynamic data for the solubility of ye'elimite from $[39]\left(\Delta \mathrm{G}_{\mathrm{f}}^{\circ}=-7929.5 \mathrm{~kJ} / \mathrm{mol}\right.$ for $\left.\mathrm{Ca}_{4}\left(\mathrm{Al}_{6} \mathrm{O}_{12}\right) \mathrm{SO}_{4}\right)$.

GEM-Selector is a broad-purpose geochemical modelling code which computes equilibrium phase assemblage and speciation in a complex chemical system from its total bulk elemental composition. The activity of a species $i,\{i\}$, is calculated with GEM-Selector from the measured concentrations in $\mathrm{mol} / \mathrm{kg} \mathrm{H}_{2} \mathrm{O}$, $m_{i}$, considering the formation of aqueous complexes as $\{i\}=m_{i} \gamma_{i}$, where $\gamma_{i}$ is the dimensionless activity coefficient. The activity coefficients of the aqueous species $\gamma_{i}$ were computed with the built-in extended Debye-Hückel equation with common ion-size parameter $a_{i}$ of $3.67 \AA$ for $\mathrm{KOH}$ solutions and common third parameter $b_{y}$ according to Equation 3:

$$
\log \gamma_{i}=\frac{-A_{y} z_{i}^{2} \sqrt{I}}{1+B_{y} a_{i} \sqrt{I}}+b_{y} I \text { Equation } 3
$$

where $z_{i}$ denotes the charge of species $i, I$ the effective molal ionic strength in $\mathrm{mol} / \mathrm{kg} \mathrm{H}_{2} \mathrm{O}, b_{y}$ is a semiempirical parameter $\left(\sim 0.123 \mathrm{~kg} \mathrm{H} 2 \mathrm{O} / \mathrm{mol}\right.$ for $\mathrm{KOH}$ electrolyte at $\left.25^{\circ} \mathrm{C}\right)$, and $\mathrm{A}_{y}$ and $\mathrm{B}_{y}$ are $\mathrm{P}, \mathrm{T}$-dependent coefficients; at $25^{\circ} \mathrm{C}$ and 1 bar pressure, $A_{y} \approx 0.5114$ and $B_{y} \approx 0.3288$. This activity correction is applicable up to approx. $1 \mathrm{M}$ ionic strength. 
This thermodynamic data were used to calculate the solubility of different hydrates under equilibrium conditions as a function of calcium, aluminium, sulphur and potassium concentrations within the system CaAl-S-K- $\mathrm{H}_{2} \mathrm{O}$ and plotted as lines in 2-dimensional and as surfaces in 3-dimensional plots within the concentration range $0.01 \mathrm{mM}$ to $100 \mathrm{mM}$. The $\mathrm{K}^{+}$concentration was varied from 1 to $200 \mathrm{mM}$ to assess the effect of $\mathrm{pH}$. The hydrates considered include hemihydrate, gypsum, portlandite, monosulfate, $\mathrm{CAH}_{10}$, $\mathrm{C}_{2} \mathrm{AH}_{7.5}, \mathrm{C}_{4} \mathrm{AH}_{13}, \mathrm{C}_{3} \mathrm{AH}_{6}$, gibbsite and amorphous as well as microcrystalline aluminium hydroxide. The limited number of the phases considered was to facilitate and accelerate the calculations. The selection of phases included into the calculations has no impact on the results as interactions neither among the phases nor between phases and the solution were considered.

The solubility line or surface for a given phase corresponds to the concentrations at saturation (saturation index $\mathrm{SI}$ is 0 ). The saturation index is defined as:

$$
S I=\log \left(\frac{I A P}{K_{s p}}\right) \text { Equation } 4
$$

where $I A P$ is the ion activity product, i.e. the concentrations of the involved species in the investigated space and $K_{s p}$ is the solubility of the given phase. If the $\mathrm{Sl}$ is higher than 0 , i.e. above the line or surface, the solution is oversaturated, below it $(\mathrm{SI}<0)$ is undersaturated with respect to that specific phase. The undersaturation with respect to the dissolving ye' elimite was calculated as well. However, the solubility of the ye' elimite was decreases by 20 log units to make plotting of its solubility line into graphs with the hydrated phases possible. This was needed since the solubility of ye'elimite is significantly higher than the ones of hydrates. The reduced solubility line is market as $\mathrm{Y}-20$ in graphs.

\subsection{Pore solution data}

Finally, the calculated solubility curves and surfaces were compared with the available experimental data on the pore solution concentrations. This enables the kinetic path of the early reaction of ye'elimite to be tracked as well as the path through the solubility curves and surfaces of the hydrates based on the evolution 

the setting time of the cement. [21] [40].

\section{Results and discussion}

of the pore solution. For the reaction of the pure ye'elimite early age solution data published in [9] were used, where the ye'elimite hydration was investigated at $w / b=100$ and 40 allowing the solution concentrations to be followed during the early reaction. For the reactions occurring in cement clinkers, the pore solution data from Zajac et al. [20] were used, where an industrial BYF clinker had been studied. The clinker contained belite, ye'elimite and ferrite phase as the main components. In the industrial clinkers ye'elimite reacts first, while the hydration of belite and ferrite phases occurs only after days of hydration [20]

\subsection{Solubility lines in Ca-Al-H2O system}

The solubility curves of the hydrated phases in the $\mathrm{Ca}-\mathrm{Al}-\mathrm{H}_{2} \mathrm{O}$ and the $\mathrm{Ca}-\mathrm{Si}-\mathrm{H}_{2} \mathrm{O}$ systems have been used to interpret the hydration of the calcium alumina and calcium silicate phases, respectively [41] [28]. The solubility diagram of $\mathrm{Ca}-\mathrm{Al}-\mathrm{H}_{2} \mathrm{O}$ has been used to explain the early hydration of the calcium alumina cement (CAC), and particularly the effect of $\mathrm{C}_{12} \mathrm{~A}_{7}$ on the acceleration of the hydration of the CA phase and on the resulting phase assemblage [42] [43]. Upon contact with water, the CA phase from CAC dissolves and the solution concentrations increase with a $\mathrm{Ca} / \mathrm{Al}=0.5$ (as indicated by the dotted $\mathrm{CA}$ line in Figure 1 ). The solution is always supersaturated with respect to aluminium hydroxide as soon as CA starts to dissolve. With ongoing dissolution highlighted by the dotted line, the solution intersects the solubility line of $\mathrm{CAH}_{10}$ phase as shown in Figure 1. However, the slow nucleation of $\mathrm{CAH}_{10}$ and aluminium hydroxide results in a long induction period of the CAC. The presence of small amounts of $C_{12} A_{7}$ phase increases the $C a / A l$, such that the solution crosses earlier the solubility curve of $\mathrm{C}_{2} \mathrm{AH}_{7.5}$ which nucleates and precipitates rapidly, shortening 

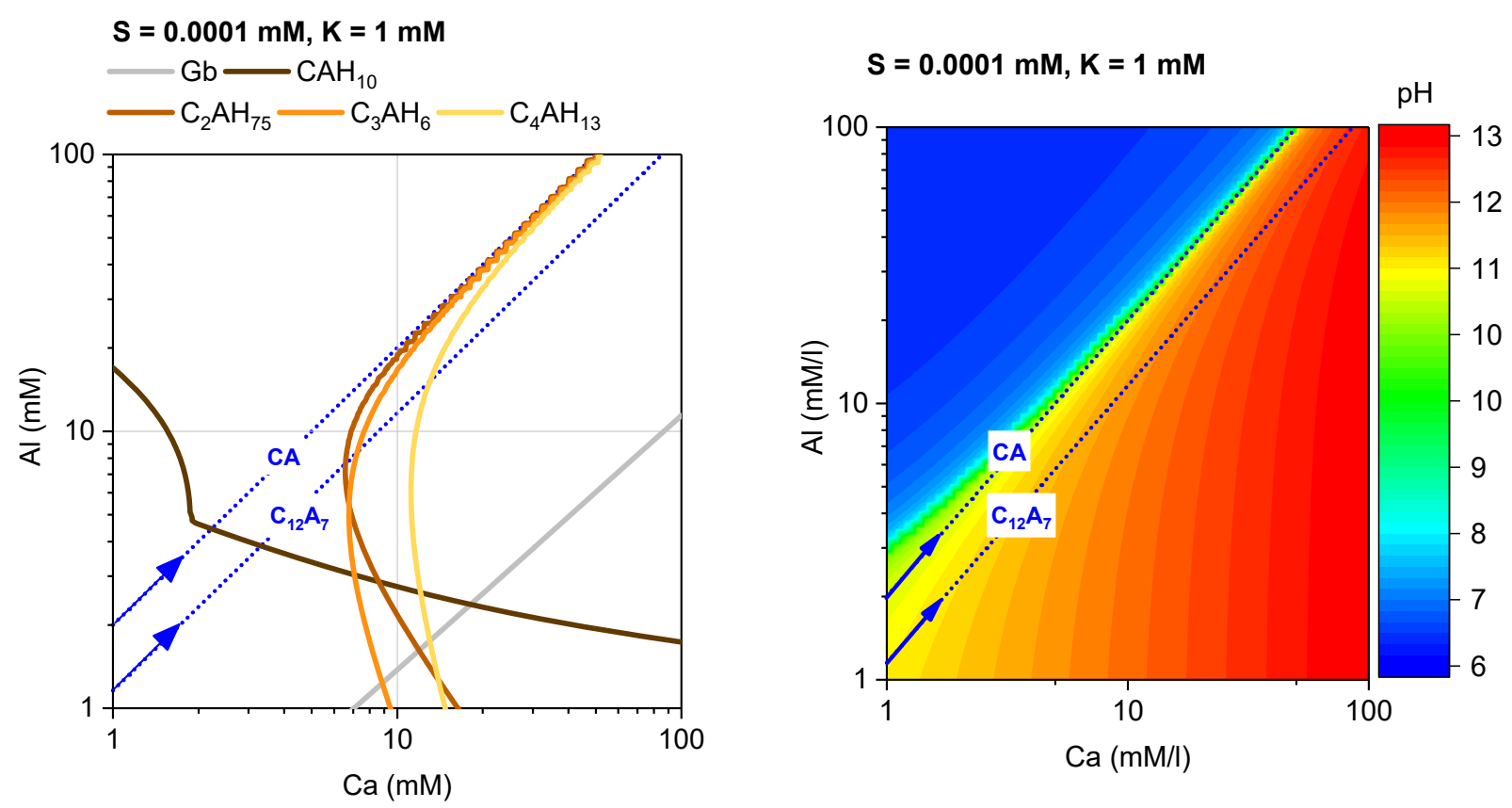

Figure 1 Left: Solubility lines for the relevant hydrates formed during the hydration of CAC, Gb - gibbsite. Below the lines the respective solid is undersaturated and cannot precipitate. Increase of the solution concentration across the line will cause that the hydrate (solid) can form as it is thermodynamically more stable than the solution. Right: pH map in the calcium alumina plane.

The arrows indicates the direction of the pore solution change during the hypothetical congruent dissolution. The doted lines are showing the evolution of the solution during the hypothetical congruent dissolution of CA and C12A7 phases. For this simulation, low $\mathrm{S}$ concentration of $0.0001 \mathrm{mM}$ and $\mathrm{K}$ equal to $1 \mathrm{mM}$ was used.

In principle, this kind of graph and analysis can also be used for the examination of the hydration of ye'elimite since it enables the solubility lines of the hydrates involved including ettringite (Et), monosulfate (MS), aluminium hydroxide $\left(\mathrm{AH}_{3}\right), \mathrm{CAH}_{10}, \mathrm{C}_{2} \mathrm{AH}_{7.5}, \mathrm{C}_{3} \mathrm{AH}_{6}$ and $\mathrm{C}_{4} \mathrm{AH}_{13}$, to be plotted at any sulphur concentration. However, this type of graph cannot be used to visualise varying sulphur concentrations or the effect of alkalis. The dissolving ye'elimite releases three different elements into the solution: $\mathrm{Ca}, \mathrm{Al}$ and sulphur. Their speciation $\left(\mathrm{Ca}^{2+} ; \mathrm{CaOH}^{+}, \ldots\right)$ changes depending on solution concentrations, which increase during the dissolution of ye'elimite. The effect of sulphur concentration is intuitive for the ettringite and monosulfate phases, since they contain sulphur. However, sulphur has an even more pronounced effect on other, sulfate- 
free, phases because of the complex interactions within the pore solution as shown in Figure 2. Similarly, the presence of the alkalis in the system has an effect on the ion speciation, ionic strength of the solution and $\mathrm{pH}$ which modifies the solubility lines and surfaces calculated for a given scenario. In this section, both these effects are illustrated and discussed. Note that $\mathrm{OH}^{-}$is not a free variable as its concentration is determined by the concentration of $\mathrm{Ca}, \mathrm{Al}, \mathrm{S}$ and alkalis, if present, and the global charge balance.

In Figure 2 the solubility lines in the $\mathrm{Ca}-\mathrm{Al}$ plane are compared for two sulphur concentrations. The solubility lines of three hydrates important for the hydration of ye'elimite: aluminium hydroxide (amorphous and gibbsite), $\mathrm{CAH}_{10}$ and ettringite, are plotted in the calcium - alumina plane in Figure 2 for sulphur concentrations of $0.1 \mathrm{mM}$ (solid lines) and $1 \mathrm{mM}$ (dashed lines). It is obvious that the sulphur concentrations influence the solubility lines of all hydrates:

- aluminium hydroxide (Figure 2 Left): the shape of the curves depends on the sulphur concentration for total $\mathrm{Ca}$ and $\mathrm{Al}$ concentration lower than $10 \mathrm{mM}$. It is noticeable that:

- At lower sulphur concentration, the solubility of aluminium hydroxide increases with increasing $\mathrm{Ca}$ concentration as this increases the $\mathrm{pH}$. At the higher sulphur concentration (which lowers the $\mathrm{pH}$ ) the curves are not monotonic. Alumina solubility decreases with increasing calcium up to $0.5 \mathrm{mM}$, while Ca concentrations $>0.5 \mathrm{mM}$ solubilise aluminium hydroxide.

- At the lower sulphur concentration, the amorphous form of aluminium hydroxide is always in equilibrium with much higher aluminium concentration than gibbsite. However, at $\mathrm{S}=1 \mathrm{mM}$ and lower Ca concentration, the difference in the aluminium concentration between the two forms becomes small.

- At $\mathrm{Ca}$ and $\mathrm{Al}$ above $10 \mathrm{mM}$, the sulphur concentration has little impact on the solubility lines of either polymorph of aluminium hydroxide.

- Ettringite (Figure 2 Right): The increasing sulphur concentration results in a shift of the solubility line at lower calcium and aluminium concentrations, while at higher $\mathrm{Al}$ and $\mathrm{Ca}$ concentrations, the increasing $\mathrm{S}$ concentration results only in a slight increase of the ettringite solubility line. It is worth noticing, that the curved solubility lines of ettringite is in equilibrium with two different aluminium concentration at calcium 

would cross the solubility line twice.

- The increasing sulphur concentration increases the solubility of the CAH10 (Figure 2 Right) phase in the range of Ca concentrations 0.1 to $\sim 3 \mathrm{mM}$. At the other Ca concentrations, the S concentration has limited impact (within the investigated range).
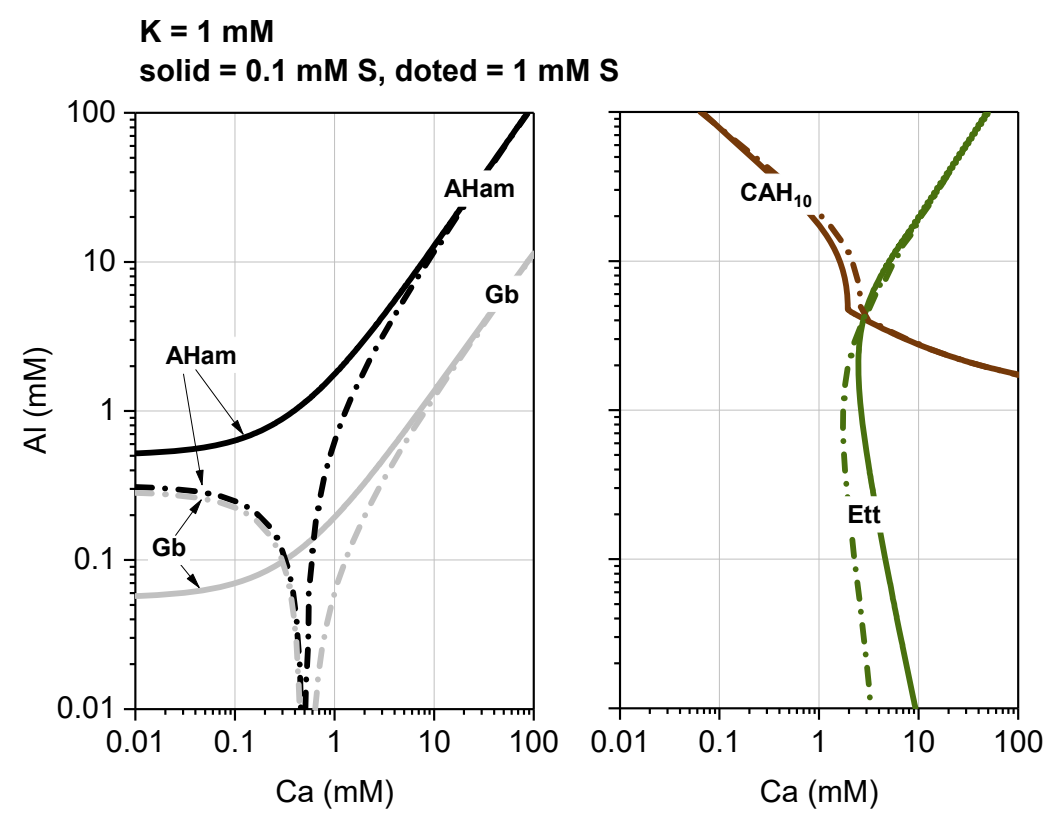

Figure 2 Solubility lines at different sulphur concentrations: $\mathrm{CAH}_{10}-\mathrm{CAH}_{10}$ phase, Ett - Ettringite, Gb - gibbsite, AHam - aluminium hydroxide amorphous. The lines are showing the transition from liquid to solid. Increase of the solution concentration across the line will cause that the hydrate (solid) is more thermodynamically stable than the solution. The solid line shown the calculation results at $0.1 \mathrm{mM}$ of $\mathrm{S}$, and doted at $1 \mathrm{mM}$ of $\mathrm{S}$. $\mathrm{K}$ concentration is $1 \mathrm{mM}$ for both cases.

The evolutions observed have two explanations, depending on the chemical composition of the hydrates:

- For the hydrates that do not contain sulphur (aluminium hydroxide and $\mathrm{CAH}_{10}$ ), the influence of the sulphur can be attributed

to the change in the ionic strength of the solution that directly impacts activity coefficients of the ions involved in the solubility products; 
$\circ$ to the complex formation between $\mathrm{Ca}^{2+}$ and $\mathrm{SO}_{4}{ }^{2-}$ in solution and

$\bigcirc$ to the lowering of $\mathrm{OH}^{-}$concentration and consequently the decrease of the pore solution $\mathrm{pH}$. It should be noted that the $\mathrm{OH}^{-}$is present in all the dissolution reactions and is coupled to $\mathrm{pH}$ via the equilibrium reaction $\mathrm{H}_{2} \mathrm{O} \rightarrow \mathrm{OH}^{-}+\mathrm{H}^{+}$. For example the dissolution reactions of aluminium hydroxide and $\mathrm{CAH}_{10}$ are at high $\mathrm{pH}$ as follows: 

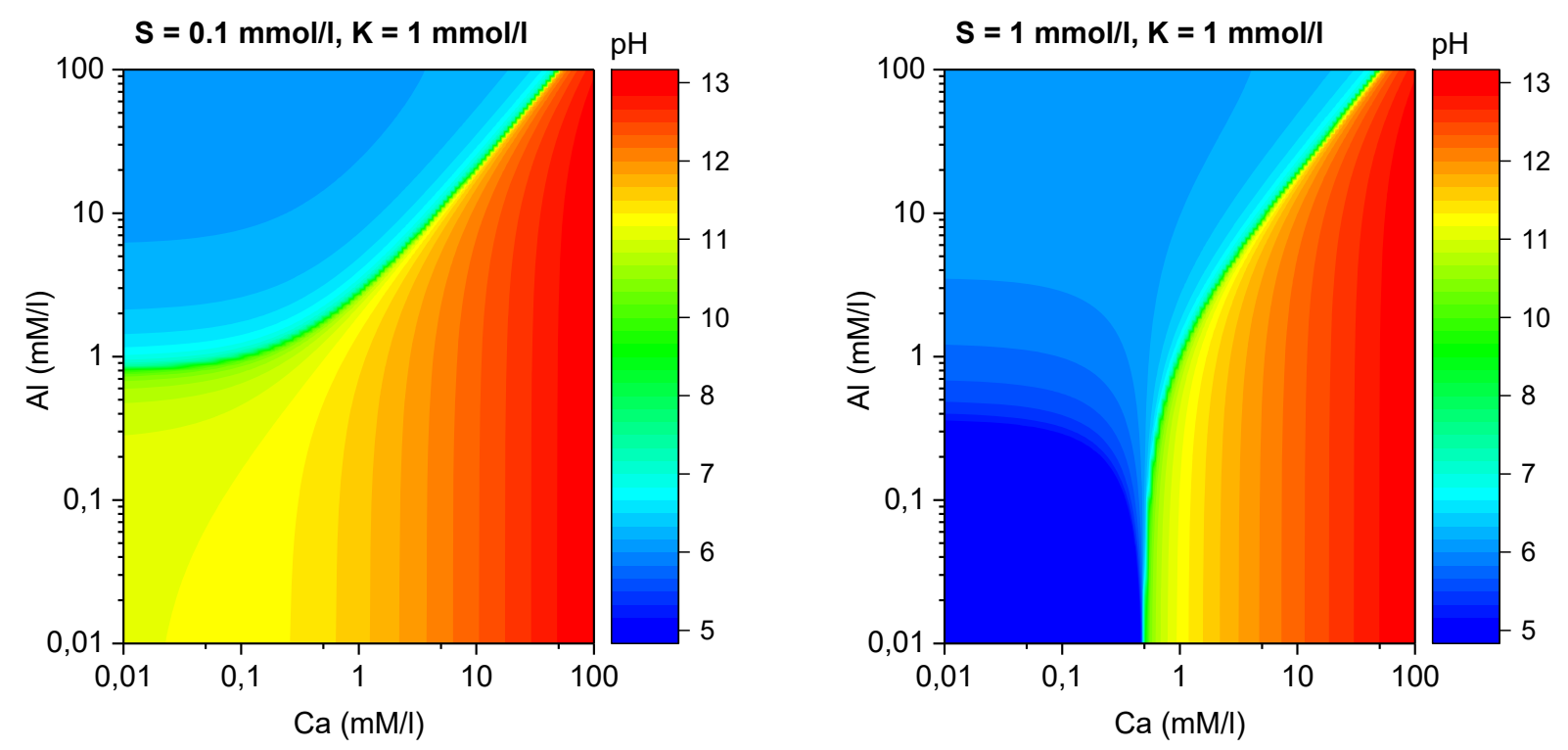

Figure $3 \mathrm{pH}$ maps in the calcium alumina planes at the two sulphur levels 0.1 and $1 \mathrm{mM}$.

215 The effect of potassium on the solubility of the aluminium hydroxide, $\mathrm{CAH}_{10}$ phase and ettringite is shown in

216 Figure 4. Potassium increases both the ionic strength of the solution as well as its $\mathrm{pH}$. This results in higher

217 aluminium concentrations in the presence of aluminium hydroxide and in a shift of the solubility line of 218 ettringite to lower $\mathrm{Ca}$ and $\mathrm{Al}$ concentrations. The effect on $\mathrm{CAH}_{10}$ is non monotonic. At lower $\mathrm{Ca}$ concentration $219(<3 \mathrm{mM})$, potassium lowers the Al concentrations. However, at high Ca concentrations $(>3 \mathrm{mM})$, more $\mathrm{Al}$ is 220 expected in the presence $\mathrm{CAH}_{10}$. 


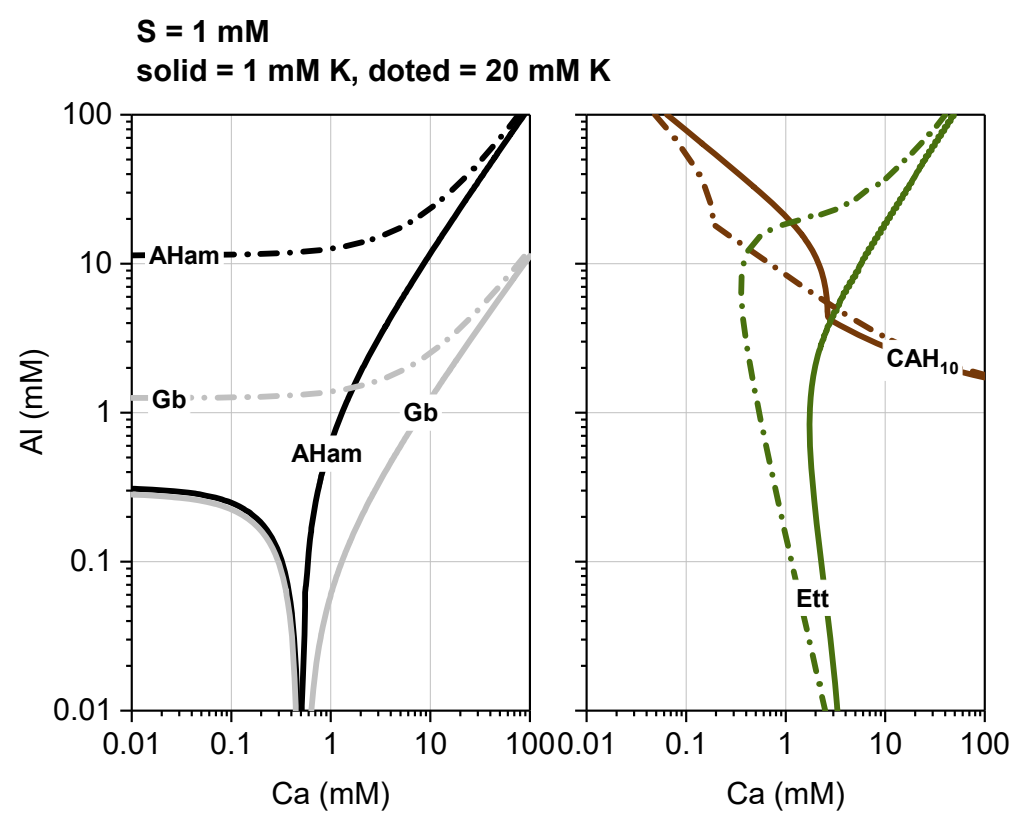

Figure 4 Solubility lines at different $\mathrm{K}$ concentrations: $\mathrm{CAH}_{10}-\mathrm{CAH}_{10}$ phase, Ett - Ettringite, Gb - gibbsite, AHam aluminium hydroxide amorphous. The solid line shown the calculation results at $1 \mathrm{mM}$ of $\mathrm{K}$, and doted $20 \mathrm{mM}$ of K. Sulphur concentration is $1 \mathrm{mM}$ in both cases.

\subsection{Three dimensional representation of the system}

As shown above the interactions in the pore solution in the $\mathrm{Ca}-\mathrm{Al}-\mathrm{S}-\mathrm{K}-\mathrm{H}_{2} \mathrm{O}$ system are complex as the sulphur and potassium have a strong impact on the ionic strength, on complex formation and the $\mathrm{pH}$ of the solution. These in turn significantly affect the solubility lines even of sulfate-free hydrates. Since the dissolution of ye'elimite provides $\mathrm{Ca}, \mathrm{Al}$ and sulphur to the solution, the analysis of solubility lines plotted in 2-dimensions cannot capture the complexity of these systems and plots in 3-dimensions showing solubility surfaces instead of lines are better suited. The three-dimensional diagram of solubility surfaces in the systems Ca-Al-S- $\mathrm{H}_{2} \mathrm{O}$ is shown in Figure 5 in the range of 0.01 to $100 \mathrm{mM} \mathrm{Ca}, \mathrm{Al}$ and sulphur at $\mathrm{K}=1 \mathrm{mM}$. The surfaces for the phases Ett, aluminium hydroxide (gibbsite), $\mathrm{CAH}_{10}, \mathrm{C}_{2} \mathrm{AH}_{7.5}$, and $\mathrm{C}_{4} \mathrm{AH}_{13}$ are shown as well as the theoretical dissolution line of stoichiometric ye' elimite. It is noticeable that solubility surfaces of Ett, $\mathrm{C}_{2} \mathrm{AH}_{7.5}$, and $\mathrm{C}_{4} \mathrm{AH} \mathrm{H}_{13}$ are close to each other (note however the logarithmic scale) and their mutual distance as well as their crossings vary depending on the concentrations in the pore solution. Note that the solubility surface of monosulfate closely follows that of ettringite in the scenario modelled. The solubility surfaces of the remaining two hydrates, aluminium hydroxide and $\mathrm{CAH}_{10}$, are distinctly different. While $\mathrm{CAH} \mathrm{H}_{10}$ is 
supersaturated only for high Al concentrations irrespective of those of calcium and sulphur, the solutions will

237

238 239 240 241

be supersaturated with respect to aluminium hydroxide for practically any concentration, except at very high sulphur and calcium concentrations. Counter intuitively, the aluminium hydroxide solubility surface is the most complex one, inspite of there being no calcium of sulphur in aluminium hydroxide. The complex shape of the surface is a result of the interactions in the pore solution and their impact on $\mathrm{pH}$. Note that the solubility surfaces of the different forms of aluminium hydroxide (amorphous, microcrystalline, crystalline) have a similar shape and are only 'shifted' along the vertical axis with aluminium concentration

Additionally, Figure 5 shows that during the theoretical calculated dissolution of the ye'elimite in pure water, the solution is oversaturated with respect to several hydrates in the order aluminium hydroxide, $\mathrm{CAH}_{10}$ and ettringite. Finally, the solution becomes supersaturated with the respect to the remaining hydrates investigated, if precipitation is not considered.

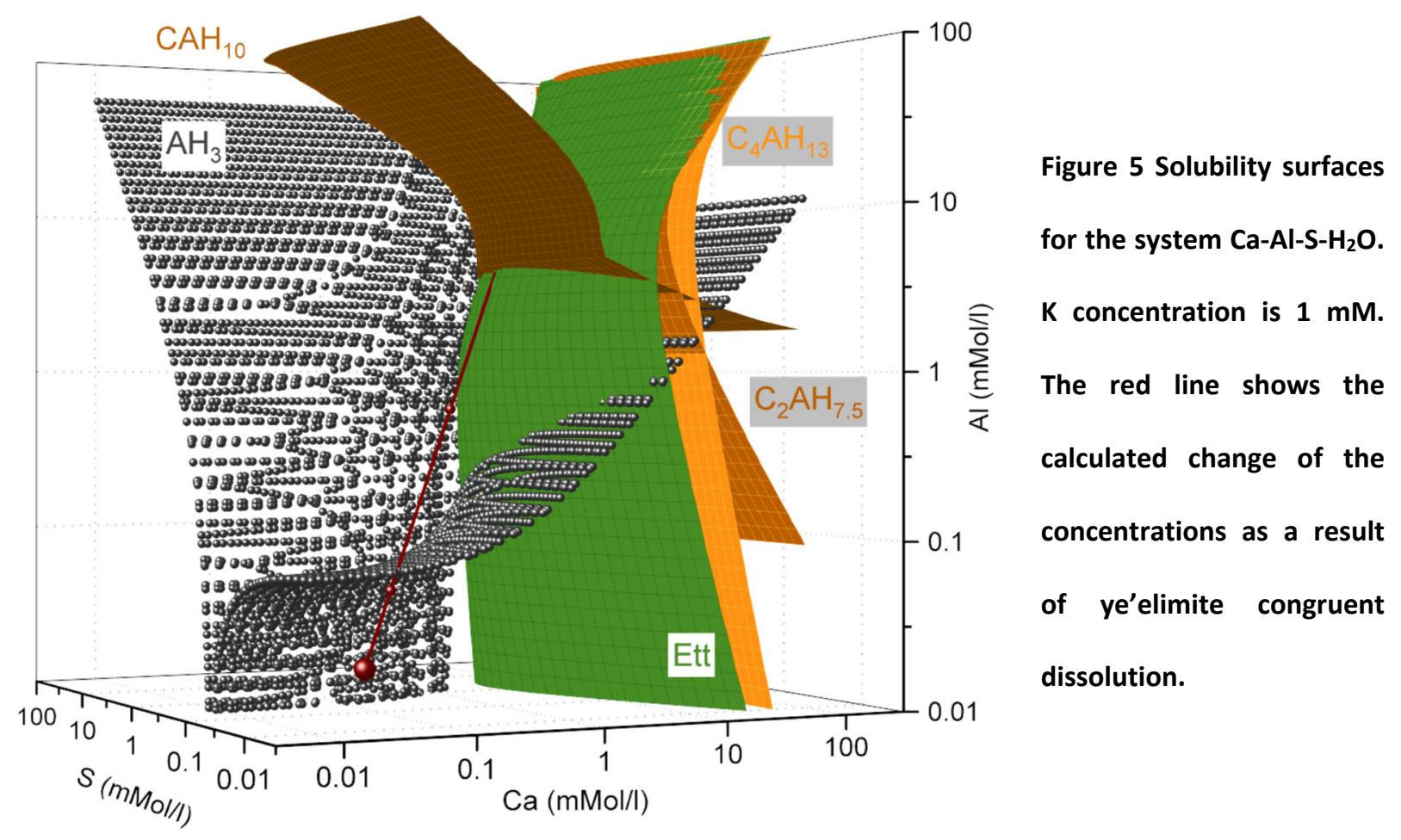

248 So far, only generic results of the thermodynamic model have been considered and the complexity resulting 249 from the interactions in multi-species solutions of high ionic strengths discussed. The key messages are 250 following: 
- Hydration reactions in Ca-Al-S-K- $\mathrm{H}_{2} \mathrm{O}$ system cannot be analysed based on total concentrations and a model accounting for speciation at high ionic strength is necessary.

- Solubility surfaces of phases are complex and highly dependent on activities of all ions including those not involved in the solubility product equation.

At the initial stage of hydration, some phases such as aluminium hydroxide are very sensitive to even small changes in alkali or sulphur concentrations. 


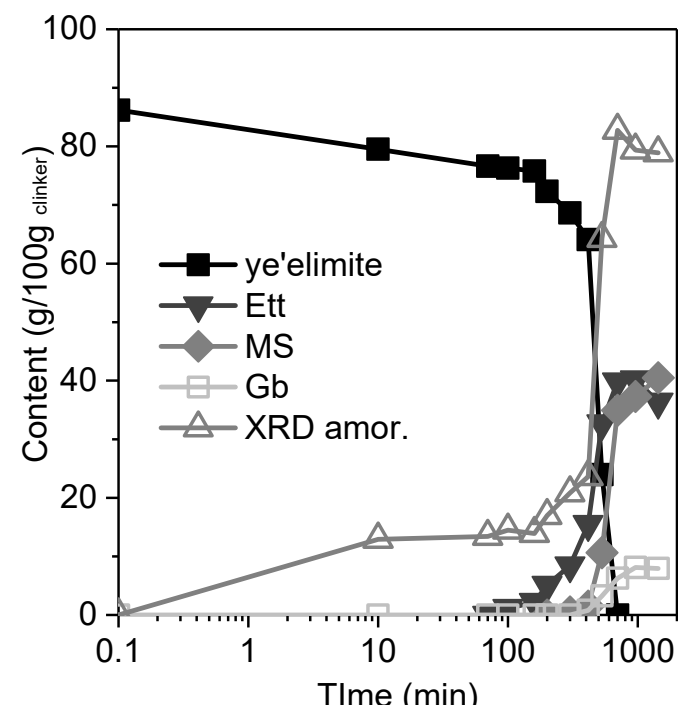

Figure 6 Evolution of the content of chosen phases during hydration of synthetic ye'elimite. Data replotted from [9].

272 Figure 7 shows the measured concentrations in the pore solution and calculated saturation indexes. The Ca,

$273 \mathrm{Al}$ and sulphur concentrations increase in parallel up to about 90 minutes. During this period, little ye'elimite 274 reaction is observed. Between 90 minutes and 400 minutes, the solution changes with strongly increasing Al 275 concentration and a drop in sulphur. Finally, the concentrations decrease. The saturation indexes confirm 276 that the main hydration products are ettringite and monosulphate as described above when discussing XRD 277 data. Additionally, they suggest that the amorphous phase is composed of aluminium hydroxide and $\mathrm{CAH}_{10}$ 278 phase [9].
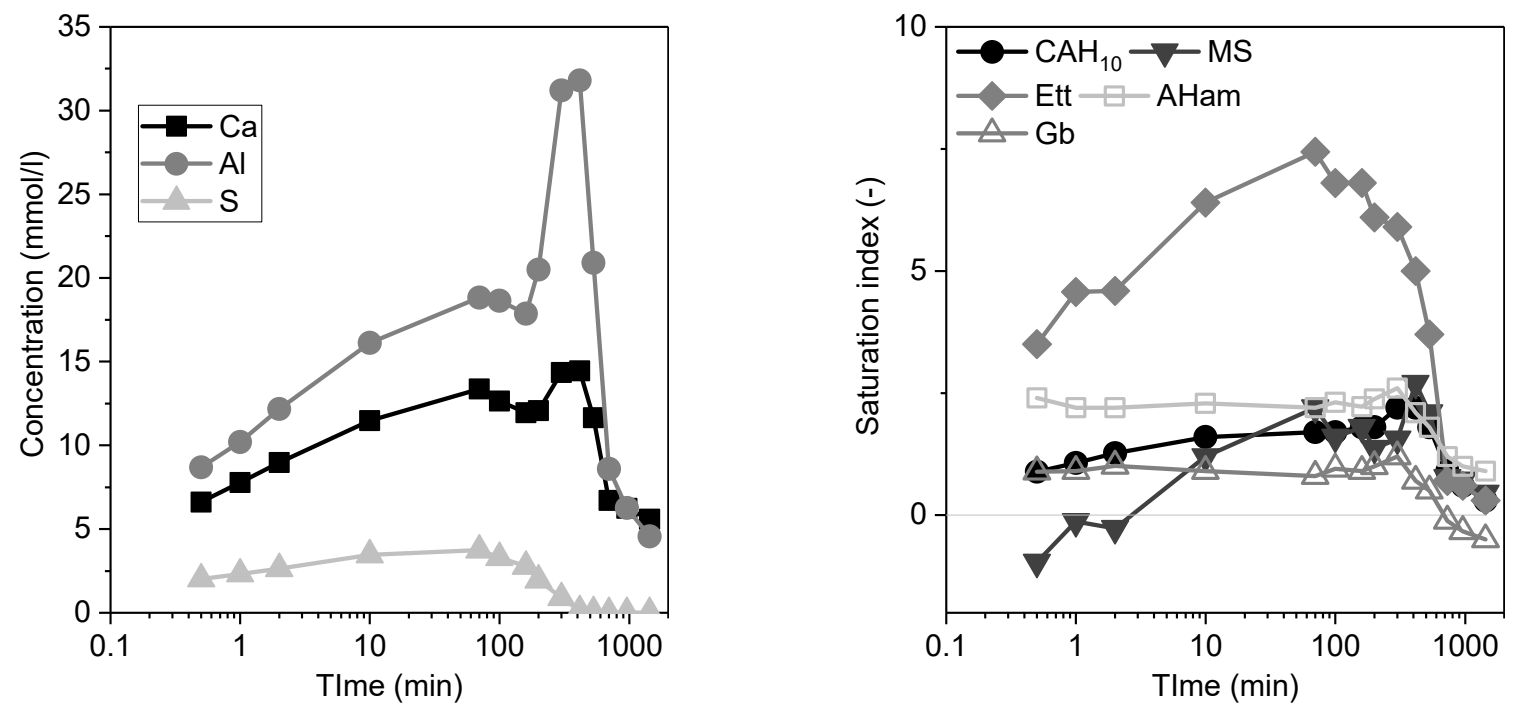

Figure 7 Pore solution concentrations measured during the reaction of ye'elimite at $w / s=40$ in pure water. Measured concentrations from [9] 
In Figure 8 the measured pore solution concentrations from Figure 7 and [9] are compared with the calculated solution concentration change during the pure dissolution of ye'elimite in pure water (indicated by the red line) and the solubility surface of ettringite. The first measurements point ( 30 seconds) lies on the calculated theoretical dissolution of ye'elimite indicating that the pore solution concentrations are changing according to the theoretical dissolution line and no solids or a solid with a composition comparable to ye'elimite have precipitated. The congruent dissolution path is followed up to about 90 minutes where maximum solution concentrations of $15 \mathrm{mM} \mathrm{Ca}, 20 \mathrm{mM} \mathrm{Al}$ and $4 \mathrm{mM}$ sulphur are reached.
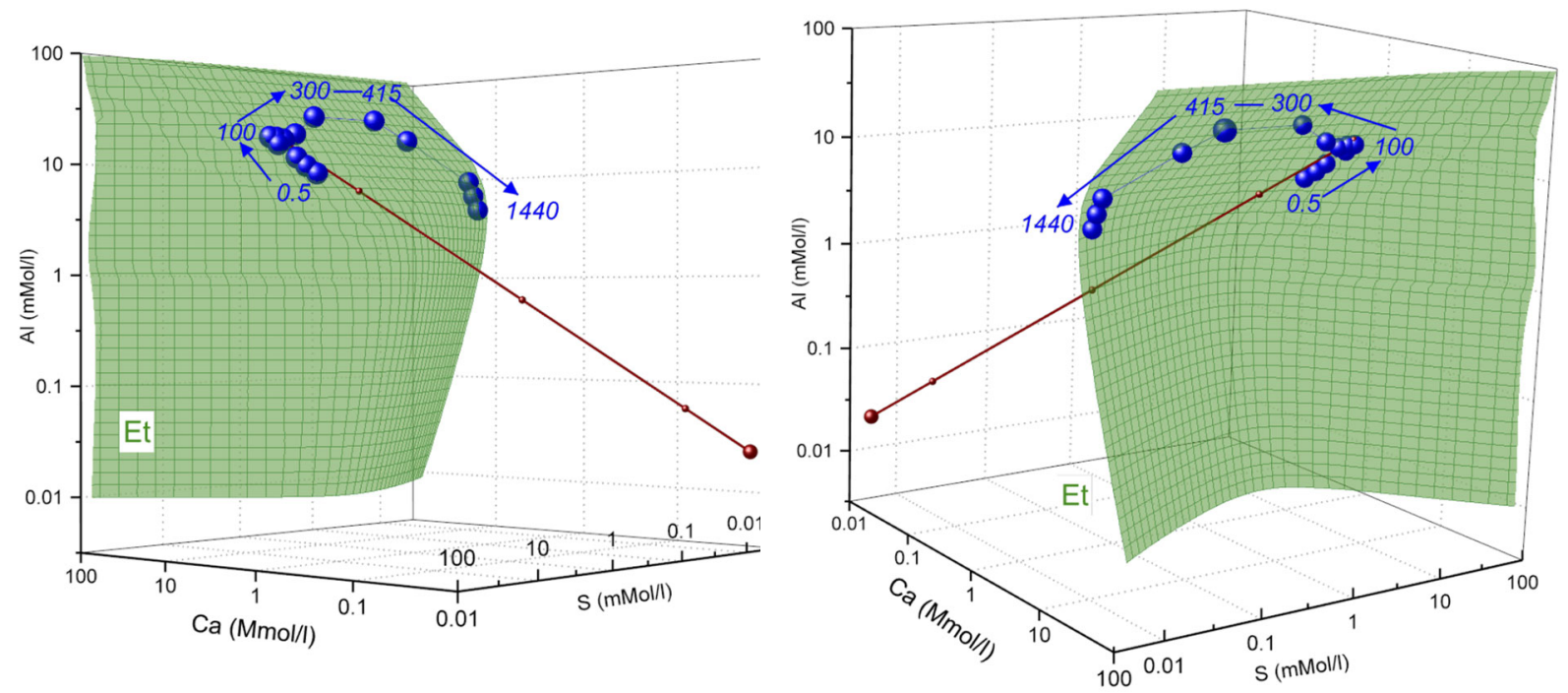

Figure 8 Solubility surface of ettringite calculated at $1 \mathrm{mM} \mathrm{K}$ compared to the theoretical dissolution line of ye'elimite (red) and measured concentrations of $\mathrm{Ca}, \mathrm{Al}$ and S during the reaction of the synthetic, pure ye'elimite at $w / c=100$ (blue points) [9]. The first measurement point is after 30 seconds. The arrows indicate the time evolution of the pore solution and the numbers the time of measurement in minutes. Both graphs show the same results but viewed from different perspective.

After 90 minutes, the concentrations deviate from the congruent dissolution line, indicating the formation of a solid rich in calcium and sulfate. During the further reaction of ye' elimite, the measured pore solution concentrations stay close to the surface of ettringite and other hydrates (Figure 8 and compare to [9]) . 
While the 3 D-graphs allow all surfaces at to be plotted at the same time, the level of complexity in such graphs is very high, consequently only intersections of surfaces from Figure 5 with different sulphur levels are plotted in Figure 9 to facilitate the discussion of the results. Additionally, the 2 D-graphs show all three crystallinities of aluminium hydroxide.
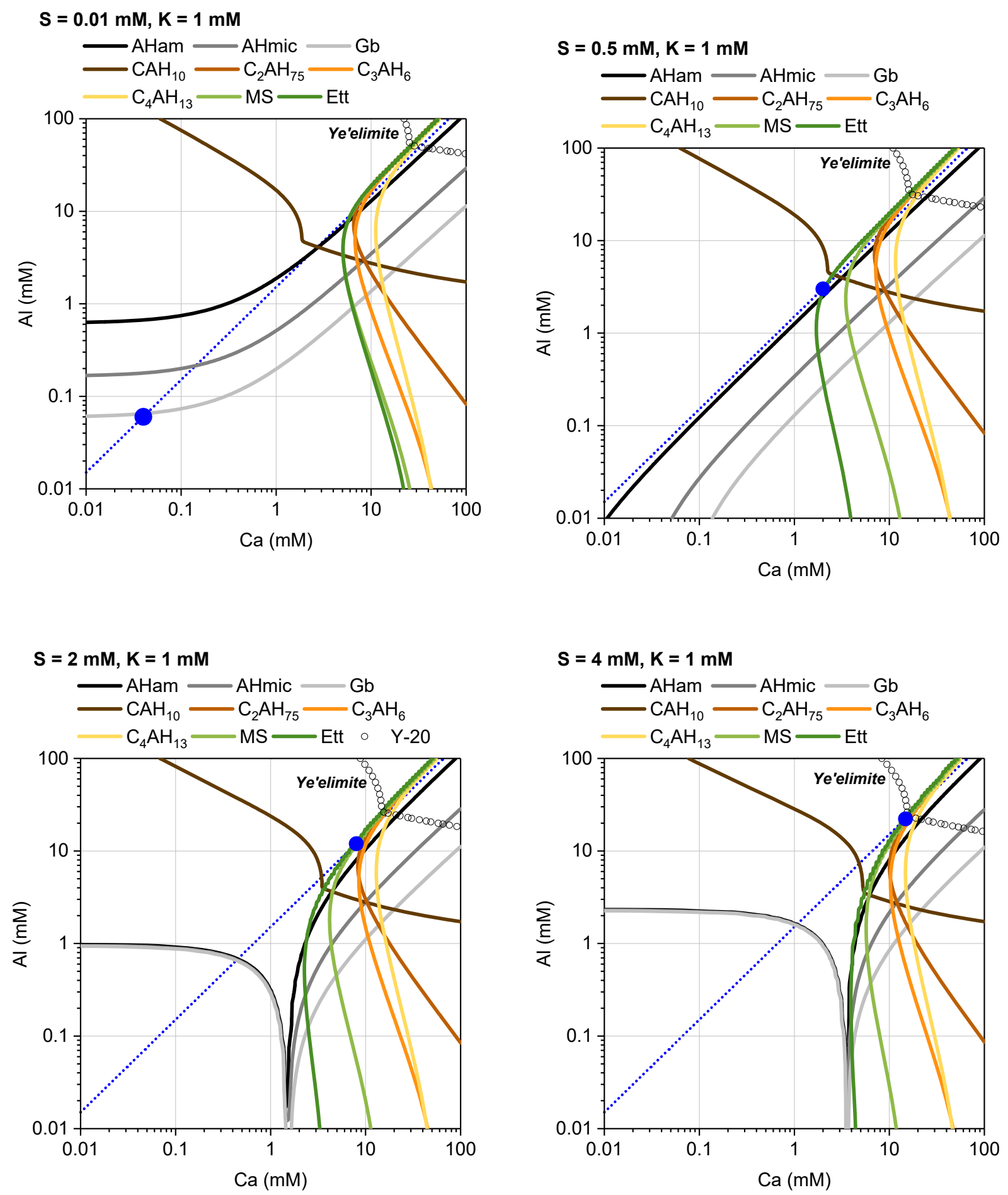
Figure 9 Intersections of surfaces from Figure 5 at different sulphur concentrations: $C_{10} H_{10}, C_{2} A H_{7.5}, C_{3} A H_{6}, C_{4} A H_{13}$, MS: monosulfate, Ett: Ettringite, Gb: gibbsite, AHmic - aluminium hydroxide microcrystalline, AHam - aluminium hydroxide amorphous. The straight dotted line shows the projection of theoretical congruent dissolution line of ye'elimite on the $\mathrm{Ca}$ - Al plane. The blue circles depict the $\mathrm{Ca}$ and $\mathrm{Al}$ concentration corresponding to the concentration of $S$ marked in the graph description. The plot at $S=2 \mathrm{mM}$ corresponds to the first measurement point at $30 \mathrm{~s}$ from hydration starting. The plot at $\mathrm{S}=4 \mathrm{mM}$ corresponds to the point after $\sim 90$ minutes of the hydration. The ye'elimite line (Y-20) depicts solubility of ye'elimite decreased for 20 log units.

For the congruent dissolution of ye'elimite, the concentrations of Al, Ca and S should increase continuously as visualised by the blue dotted line in Figure $9, \mathrm{~S}=0.01$ to $4 \mathrm{mM}$, until solids start to precipitate. This theoretical dissolution line first crosses the solubility line of gibbsite; however, the precipitation of this crystalline phase is very slow at ambient temperature, so rather amorphous or microcrystalline aluminium hydroxide forms [18]. The solubility lines of the microcrystalline and amorphous forms of aluminium hydroxide would be crossed at very low sulphur concentrations. However, in parallel to the $\mathrm{Al}$ and Ca concentration, also the sulphur concentration increases, which lowers the $\mathrm{pH}$ values and changes the solubility lines of aluminium hydroxide as had been discussed above for Figure 2. Thus, the further increase of the solution concentrations does not result in significant increases in supersaturation with respect to amorphous aluminium hydroxide (Figure $9 \mathrm{~S}=0.5,1$ and $4 \mathrm{mM}$ ) as the slope of the surface of AHam is similar to the dissolution curve of ye'elimite at sulphur concentrations larger than $\sim 0.5 \mathrm{mM}$. At later times of dissolution, i.e. at sulphur concentrations above $0.5 \mathrm{mM}$, the theoretical dissolution line of ye' elimite crosses the solubility line of ettringite followed by $\mathrm{CAH}_{10}$ phase. Further dissolution of ye'elimite results in continuous increases of the supersaturation against the $\mathrm{CAH}_{10}$ phase. However, the supersaturation with respect to ettringite is limited because of the shape of its solubility surface almost parallel with the dissolution line (compare with calculated SI in Figure 6). The experiments with a pure ye'elimite ([9], Figure 7 and Figure 6) demonstrate that the solution composition follows, after the first 90 minutes, the trend of the solubility surface of ettringite, as also mirrored in the only moderate oversaturation of ettringite. Finally, it is noticeable that during the first minutes of ye'elimite dissolution, the undersaturation with respect to monosulfate 
continuously increases. Only at the intermediate stages (after 400 minutes) of the dissolution reaction when the elements concentrations increase, monosulfate becomes oversaturated (corresponding to sulphur concentration close to $4 \mathrm{mM}$ ). Gypsum is continuously undersaturated for all concentrations studied.

The shape of the solubility surfaces of the main hydrates is such that the continuous increase of the Al, Ca and sulphur results in a relatively small increase of the supersaturation against the main hydrated phases and thus in a relatively slow nucleation and precipitation, which explains the slow initial reaction of the synthetic neat ye'elimite observed by calorimetry [9].

This low oversaturation occurs because gibbsite does not precipitate fast enough and only the amorphous form of aluminium hydroxide precipitates to small extend during the first hours of ye'elimite reaction [9]. A massive precipitation of gibbsite would deplete Al from the solution and the dissolution line would follow the gibbsite surface instead of the congruent dissolution line in Figure 9. In such a case, the saturation surfaces of ettringite and monosulfate would be crossed sooner (see Figure 9 at $S=2$ and $4 \mathrm{mM}$ ) such that the supersaturation with respect to ettringite and monosulfate would increase more rapidly leading to earlier and more intense nucleation and precipitation of these two phases. A significant precipitation of $\mathrm{CAH}_{10}$ (Figure 9, $\mathrm{S}=2$ and $4 \mathrm{mM}$ ) would have a similar effect, though less pronounced, and would lead to an earlier nucleation and precipitation compared to the stoichiometric ye'elimite dissolution. In fact, the plot of the experimental data and the congruent solubility curve illustrates that a small quantity of aluminium richhydrates has precipitated [9] during the early hydration as shown in Figure 10. This lowers the aluminium concentrations and results in a faster increase of the supersaturation which respect to the ettringite and later on monosulfate than if no phase had precipitated. 


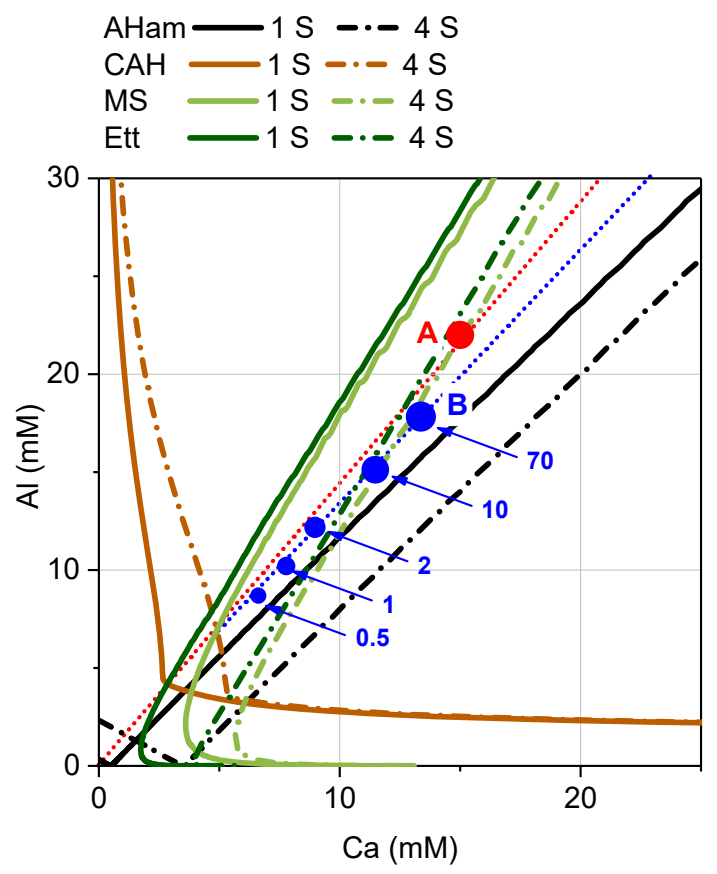

Figure 10 Intersections of surfaces of $\mathrm{CAH}-\mathrm{CAH}_{10}, \mathrm{MS}$

- monosulfate, Ett - Ettringite, and AHam -

aluminium hydroxide amorphous at 1 and $4 \mathrm{mM}$

sulphur concentrations. The straight red dotted line

shows the projection of theoretical dissolution line of

ye'elimite on the $\mathrm{Ca}-\mathrm{Al}$ plane. The blue points show

the measured pore solution centration evolution

during the first $\mathbf{7 0}$ minutes (numbers gives the

measurement time). Point B shown the measured

concentrations rat the highest sulphur level ( $4 \mathrm{mM}$

S) while point A represents the theoretical $\mathrm{Ca}$ and $\mathrm{Al}$

concentration assuming no precipitation.

Figure 11 shows the evolution of the measured pore solution concentrations between 90 minutes and 700 minutes of hydration at $w / b=40$. It is noticeable that the increase of the alumina concentration at the end of the dormant period is related to two phenomena:

- Hydrates precipitation leads to the accumulation of the alumina in pore solution, indicating the slower precipitation of AHam already discussed

- The decrease of the sulphur concentration increases the $\mathrm{pH}$ of the pore solution and the shape of the solubility surface such that monosulfate and ettringite continue to be supersaturated

- This increase of $\mathrm{pH}$ leads also to a change of the aluminium hydroxide solubility surfaces, such that after longer time the amorphous aluminium hydroxide becomes undersaturated and microcrystalline aluminium hydroxide starts to form (in agreement with occurrence of a more crystalline aluminium hydroxide as shown in Figure 7) 
AHam $-0.01 \mathrm{~S}-\cdot-4 \mathrm{~S}$

$\mathrm{CAH}-0.01 \mathrm{~S}-\cdot-4 \mathrm{~S}$

MS $0.01 \mathrm{~S}-.-4 \mathrm{~S}$

$\mathrm{Ett} \longrightarrow 0.01 \mathrm{~S}-\cdot-4 \mathrm{~S}$

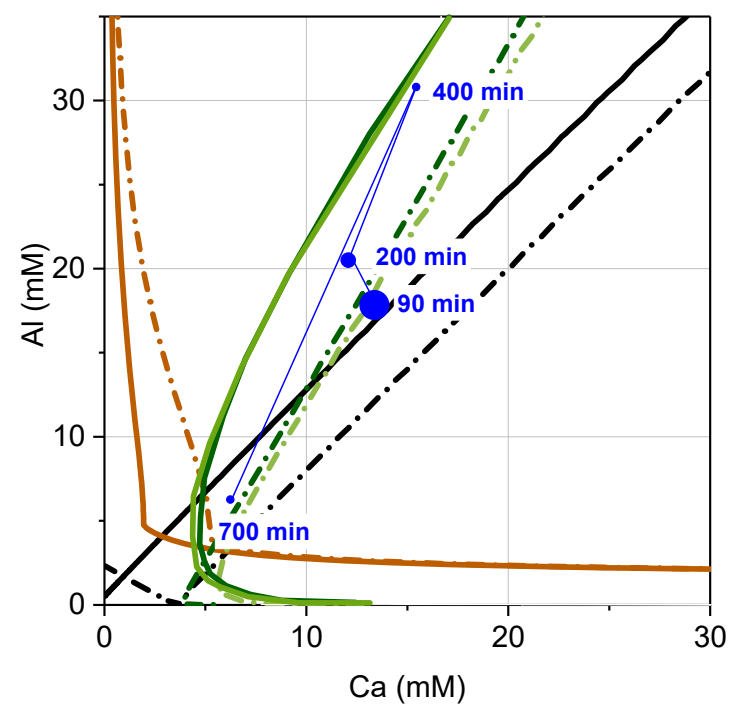

Figure 11 Intersections of surfaces of $\mathrm{CAH}-\mathrm{CAH}_{10}$,

MS - monosulfate, Ett - Ettringite, and AHam -

aluminium hydroxide amorphous at 0.01 and $4 \mathrm{mM}$

sulphur concentrations.

The blue points show the measured pore solution

centration evolution during the measurement after

90 minutes at the highest sulphur level ( $4 \mathrm{mM}$

sulphur). The other points represent the measured

data after 200, 400 and 700 minutes and low sulphur

concentrations ( $0.01 \mathrm{mM}$ sulphur after $700 \mathrm{~min}$ ).

350 Until now, we have focused on the dissolution of neat stoichiometric ye'elimite and the effects caused by

351 the interactions in the high ionic strength solution. Based on the changes to the saturation surfaces modelled,

352 the sequence of events in the dissolving and hydrating systems could be explained. Even in this simpler case,

353 the interactions were complex. Here we investigate in detail the dissolution of ye'elimite in the BYF clinker

354 and the impact of reacting rapidly phases like alkali sulphates and $C_{12} A_{7}$.

355 At the beginning of this section, the hydration of the BYF clinker is summarised, based on an earlier 356 publication [20]. The evolution of the phase assemblage at the beginning of the hydration of BYF cement is 357 dominated by the reaction of ye'elimite and principally similar to the pure ye'elimite as shown in Figure 12.

358 It is noticeable that the dormant period is significantly shorter: ye'elimite starts to rapidly react after about 359 120 minutes of hydration. 


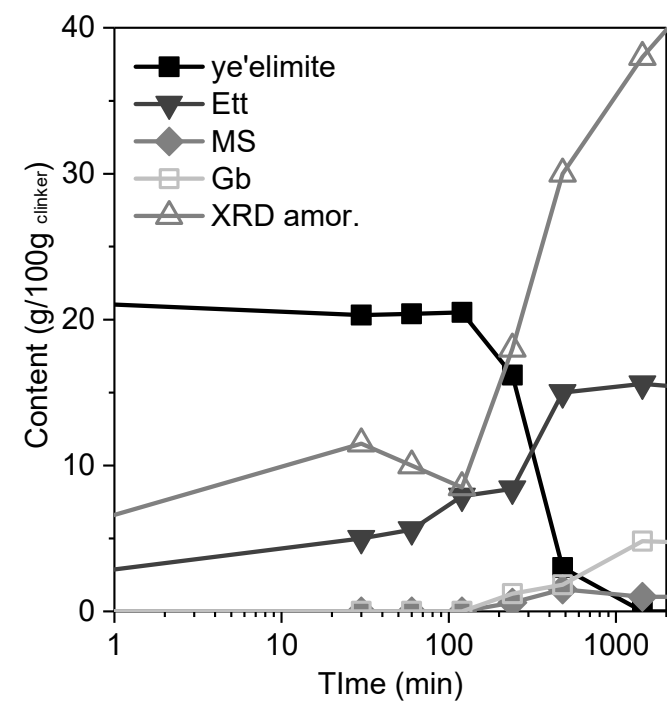

Figure 12 Evolution of the content of selected phases during BYF clinker hydration at $\mathbf{w} / \mathbf{b}=\mathbf{2}$. Data replotted from [20].

The pore solution evolution is shown in Figure 13. The evolution of the alumina concentration is similar to that of pure ye'elimite, but with significantly higher concentration values. The concentrations of calcium and sulphur are decreasing from the first measurement time, i.e. after 5 minutes from mixing with water. This indicates, in contrast to the pure ye'elimite system discussed above, precipitation of calcium and sulphur rich solids, consistent with the very early ettringite formation observed in these systems. Also, the sulphur concentrations are significantly higher than observed for the ye'elimite reacting in pure water (c.f. Figure 7). Additionally, the alkali concentration is high in industrial cements. The higher alkali concentration and high initial sulphur concentrations are related to the alkali sulphates typically present in industrial and semi industrial clinkers. Alkali sulphates dissolve almost instantly in mixing water leading to high alkali and sulphur concentrations. 

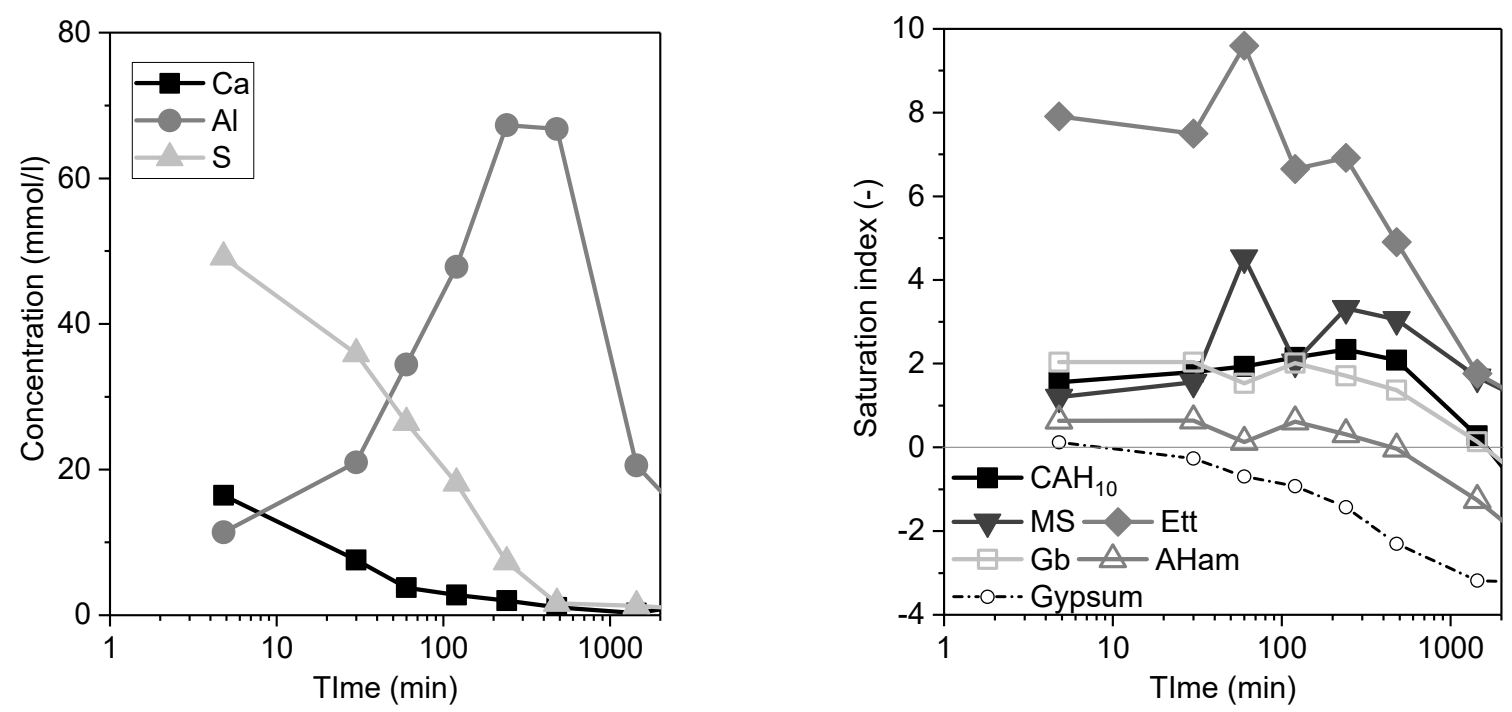

Figure 13 Pore solution concentrations measured during the reaction of BYF clinker at w/s = 2 in pure water.

\section{Measured concentrations from [9].}

These differences are also related to the presence of minor phases that are formed during the clinkering process and which significantly influence the hydration of ye'elimite in the cement. Calcium aluminate phases, $C A$ and $C_{12} A_{7}$, are often present in laboratory and industrial clinkers [12][13][14][44][45][46]. Particularly $\mathrm{C}_{12} \mathrm{~A}_{7}$ reacts rapidly during the first minutes of the cement hydration [20][45][46] and has been shown to accelerate the kinetics of the ye'elimite hydration [10].

The effect of the presence of these phases on the dissolution process is explored in Figure 14 by plotting the pore solution composition against the solubility surfaces. The solubility surfaces are calculated for alkali and sulphur concentrations corresponding to data in Figure 13. In this work, the total alkali concentration at the first measurement time was about $100 \mathrm{mM}$ and this corresponds to a sulphur concentration of $50 \mathrm{mM}$ assuming they originate from readily soluble alkali sulphates. In order to simplify the analysis, we assumed that potassium is the only alkali present and that its content does not change during the early age hydration investigated. Again, the theoretical congruent dissolution curve of ye'elimite is plotted against the crosssection of the solubility surfaces of the main hydrates at the different sulphur levels is shown in Figure 14. The theoretical dissolution line of $C_{12} A_{7}$ phase has been added (red dotted line). This $C_{12} A_{7}$ dissolution line runs nearly parallel to the ye'elimite dissolution line. 

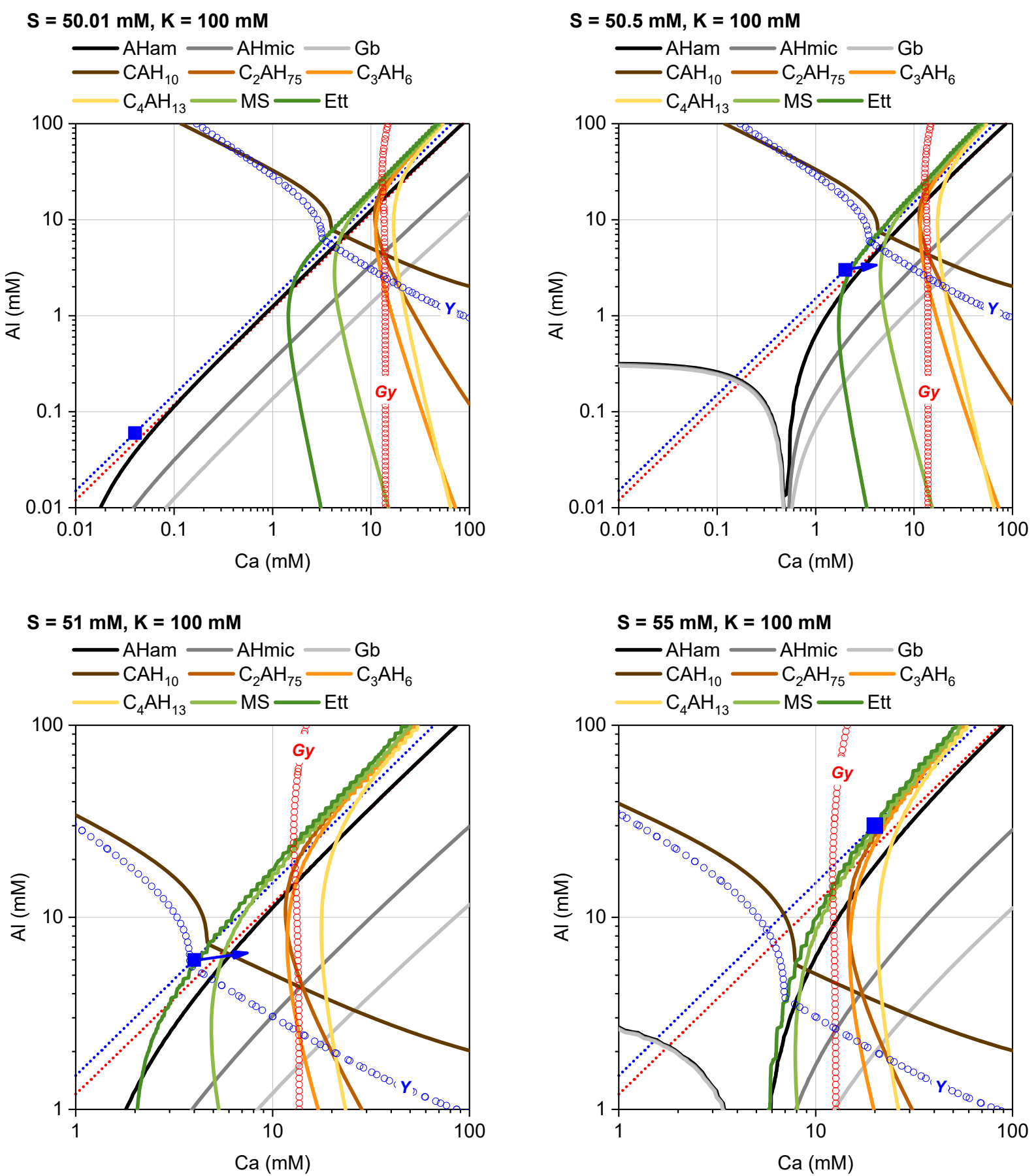

Figure 14 Intersections of solubility surfaces at different sulphur concentrations: Gy is the solubility surface of gypsum and $\mathrm{Y}$ is the ye'elimite solubility surface moved for $\mathbf{2 0} \log$ units. In the calculation, an initial concentration of $50 \mathrm{mM} \mathrm{K}_{2} \mathrm{SO}_{4}$ was assumed.

The straight blue dotted line shows the theoretical congruent dissolution line of ye'elimite. The square blue points depict the $\mathrm{Ca}$ and $\mathrm{Al}$ concentration corresponding to the concentration of sulphur indicated on the graph. The straight red dotted line shows the $\mathrm{Ca} / \mathrm{Al}$ ratio corresponding to the congruent, hypothetical dissolution of $C_{12} A_{7}$ phase. The arrow indicates the effect of $C_{12} A_{7}$ on the dissolution of ye'elimite. 
The calculations reveals that the presence of $50 \mathrm{mM}$ of $\mathrm{K}_{2} \mathrm{SO}_{4}$ in the solution (Figure 14) has a limited impact on the calculated shape of the solubility surfaces of the calcium alumina hydrates compared to the case of the dissolution of ye'elimite in pure water. The addition of only $\mathrm{K}_{2} \mathrm{SO}_{4}$ does not change the $\mathrm{pH}$ values significantly when compare to the pure water (data not shown here). Only when more sulphur is added (so the $S / K$ is increased), which lowers the $\mathrm{pH}$ values, the curves show similar shifts as observed in Figure 9; thus the concentration of sulphur of $0.01 \mathrm{mM}$ in pure water corresponds to concentration of sulphur of $50.01 \mathrm{mM}$ in $\mathrm{K}_{2} \mathrm{SO}_{4}$ solution and $0.5 \mathrm{mM}$ corresponds to $50.5 \mathrm{mM}$ and so on.

There are two noticeable changes between the calculated solubility data for the pure water case and the $\mathrm{K}_{2} \mathrm{SO}_{4}$ solution:

- Gypsum becomes supersaturated at higher calcium concentration for the case with $\mathrm{K}_{2} \mathrm{SO}_{4}$ in solution. Note that in the Figure 9 gypsum was always under-saturated.

- At each investigated sulphur level, ye'elimite is less under saturated when compared to the dissolution of the ye'elimite in the water.

The $\mathrm{K}_{2} \mathrm{SO}_{4}$ addition has a limited impact on the solubility lines of calcium alumina hydrates. Since the undersaturation with respect to ye' elimite is lower at each sulphur level when compared to pure water case, its reaction should be slower. However, the experiments provided in the literature show that ye'elimite reacts significantly faster in the industrial cements; compare the kinetics of ye'elimite dissolution in Figure 6 and Figure 12. The main reason for this acceleration is the $C_{12} A_{7}$ phase [10]. This phase has two pronounced impacts on the calculated evolution of the pore solution during the dissolution of ye'elimite:

- The dissolution of $C_{12} A_{7}$ increases the $A l$ and $C$ a concentration relative to the sulphur released from ye'elimite.

- It moves the dissolution curve of the ye'elimite towards lower aluminium and higher calcium concentrations as shown by the red dotted line in Figure 14,

These specific effects are confirmed by the pore solution concentrations measured during the dissolution of ye'elimite in the presence on $C_{12} A_{7}$ as discussed in detail in [10]. These phenomena have a pronounced impact on the development of the pore solution concentration relative to the solubility surfaces during the 
dissolution ye'elimite in the cement clinker. At any given quantity of the ye'elimite dissolved, i.e. at the given

417 increase of the sulphur concentration in Figure 14, the solution is always more supersaturated initially with 418 respect to aluminium hydroxide and later on with respect to ettringite and $\mathrm{CAH}_{10}$. Hence these phases can 419 precipitate earlier and faster. It is also noticeable that the presence of $C_{12} A_{7}$ results in a different order in 420 which the solubility surfaces are crossed during the ye'elimite dissolution. While in the case of pure ye'elimite 421 (Figure 9), the solution is supersaturated with respect to aluminium hydroxide and later on with respect to $422 \mathrm{CAH}_{10}$ and ettringite, the presence of $\mathrm{C}_{12} \mathrm{~A}_{7}$ and alkali sulfates in industrial clinkers modifies the pore solution 423 composition such that it is first supersaturated with respect to ettringite and later on with respect to $\mathrm{CAH}_{10}$. 424 Overall, these changes contribute to the acceleration of ye'elimite hydration in the industrial cements 425 compared to the reaction of neat ye'elimite in pure water.

426 Another interesting point is the effect of alkalis on the evolution described above. The alkalis present as alkali 427 sulphate and those dissolved in the rapidly hydrating clinker phases (e.g. ye'elimite [27]) dissolve rapidly 428 during the first minutes of the cement hydration, which increases the $\mathrm{pH}$ of the pore solution and affects the 429 shape of the solubility surfaces. It should be noted that in the semi industrial and industrial cements the pH 430 of the pore solution is about 1 unit higher at all stages of the hydration than in the synthetic ye'elimite 431 dissolving in water (compare the data in [9], [10], [20], [25]). The effect of the alkali dissolution is shown in 432 Figure 15 for two $\mathrm{S}$ concentrations of 50.5 and $55 \mathrm{mM}$, respectively. 

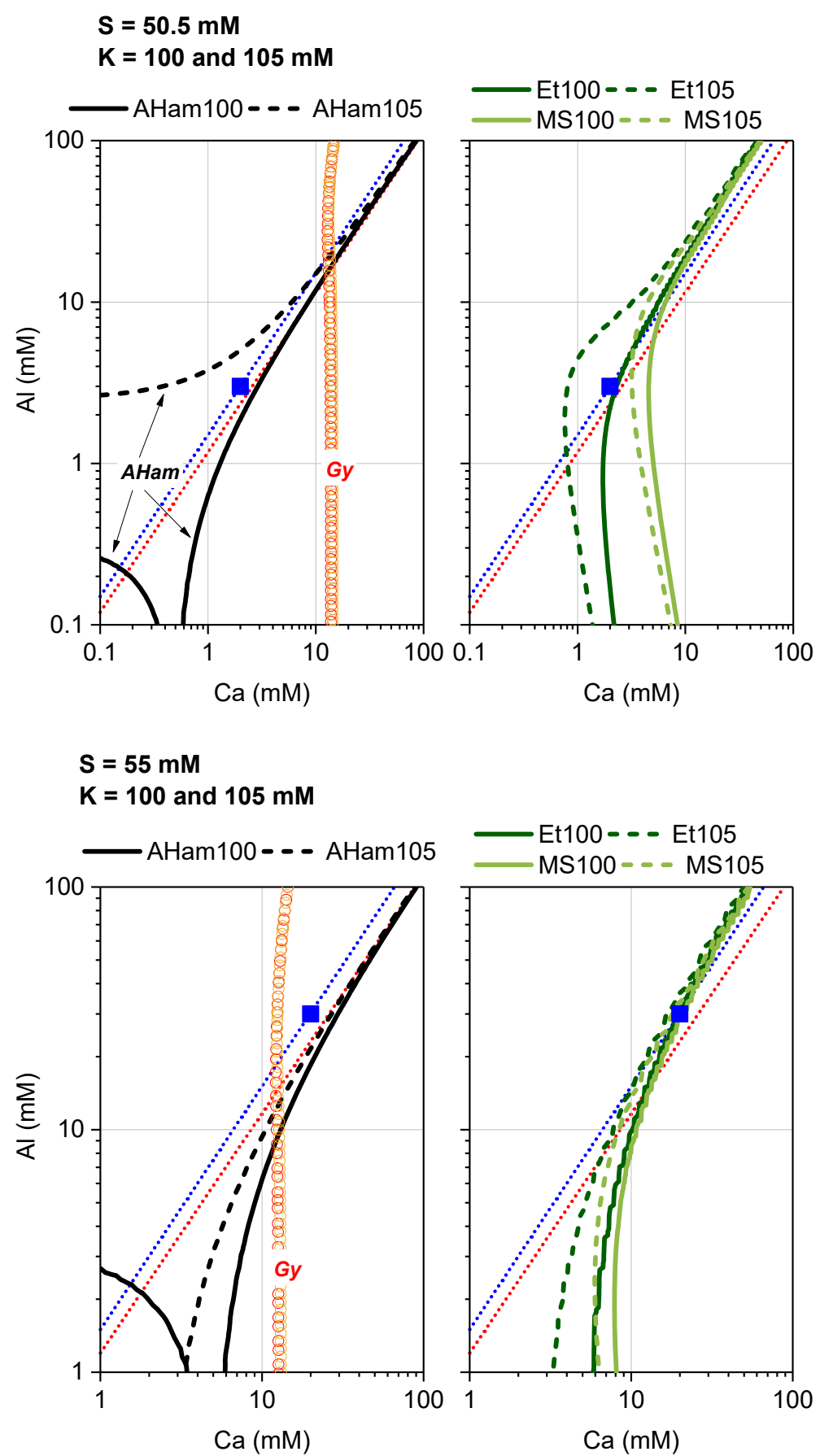

Figure 15 Intersections of solubility surfaces at $\mathrm{S}=\mathbf{5 0 . 5}$ and $55 \mathrm{mM}$ and two $\mathrm{K}$ concentrations equal to 100 and $105 \mathrm{mM}$. The straight blue dotted line shows the projection of theoretical dissolution line of ye'elimite on the Ca

- Al plane. The square blue points depict the $\mathrm{Ca}$ and $\mathrm{Al}$ concentration corresponding to $\mathrm{S}=0.5$ at $1 \mathrm{mM}$ from ye'elimite. The straight red dotted line shows the $C a / A l$ ratio corresponding to the dissolving $C_{12} A_{7}$ phase.

435 For this comparison the solubility surfaces were calculated at the alkali level $\mathrm{K}=105 \mathrm{mM}$ and compared to the $100 \mathrm{mM}$ as shown in Figure 15. It is noticeable that the increasing alkali concentration modifies the shape 
of the solubility of ettringite and monosulfate in such way that they are crossed earlier and the supersaturation increases more rapidly during the calculated dissolution of ye'elimite. Contrary, the solubility surface of aluminium hydroxide is modified in the way that the solution is initially undersaturated with respect to this phase at the higher alkali level. This can further contribute to the acceleration of the ye'elimite hydration in industrial cement when compared to the pure ye'elimite reaction. It is important to notice that the solubility surface of the gypsum is not significantly modified.

\section{Conclusions}

Thermodynamic modelling is a powerful tool to determine the variation of the system in presence of solutions having known compositions. A knowledge of the equilibrium diagram is important even if the system is dynamic (not at equilibrium) as occurs at the beginning of hydration: in fact it enables the kinetic path of the reaction to be traced and so to determine if the solution is supersaturated or undersaturated with respect to stable (or metastable hydrates if the metastable system is calculated) as mention already in the 90 s by Damidot and Glasser [30], [31] [32].

Contrary to previous studies on CAC and calcium silicates - the speciation model for high ionic strength solutions enabled us to study the Ca-Al-S- $\mathrm{K}-\mathrm{H}_{2} \mathrm{O}$ system accounting for complex interactions in the pore solution. By comparing the solubility surfaces with experimentally determined pore solution concentrations, it is demonstrated that the hydration pathways follow the stability fields of certain hydrates.

For hydration of stoichiometric synthetic ye'elimite, the evolution of the pore solution concentrations observed could be explained. During the initial dormant period, the saturation with respect to calcium bearing hydrates changes significantly less than the changes of the concentrations would suggest. This is caused by the interactions among the sulphur-bearing ionic species with alumina and calcium-bearing ones, making the saturation surfaces almost parallel to the congruent dissolution line of ye'elimite. Once hydrates start to precipitate, their supersaturation does not change as dramatically as the pore solution concentration. Again, this is caused by the specific impact of the pore solution composition on the solubility of the involved phases. 
cements and shows how the presence of alkalis and C12A7 can accelerate the kinetics of ye' elimite hydration.

While the alkalis from soluble salts such as $(\mathrm{Na}, \mathrm{K}) \mathrm{SO}_{4}$ have little impact on the hydration path, alkalis dissolved in clinker forming phases move the solubility surfaces of the hydrated phases towards lower concentrations of $\mathrm{Ca}, \mathrm{Al}$ and sulphur which accelerates the hydration process. A similar impact could be associated with the presence and dissolution of $\mathrm{C}_{12} \mathrm{~A}_{7}$ from clinker.

The qualitative as well as quantitative agreement of the modelling results with the experimental data and observations not only proves the applicability of thermodynamic modelling to assessment of the hydration of calcium sulfo-aluminates, but also enables identification of the mechanisms involved which leads, finally, to a predictive model for the hydration pathways depending on the initial conditions and material compositions.

\section{References}

[1] F. P. Glasser and L. Zhang, "High-performance cement matrices based on calcium sulfoaluminate-belite compositions," Cement and Concrete Research, vol. 31, no. 12, pp. 1881-1886, 2001.

[2] M. C. G. Juenger, F. Winnefeld, J. L. Provis, and J. H. Ideker, "Advances in alternative cementitious binders," Cement and Concrete Research, vol. 41, no. 12, pp. 1232-1243, Dec. 2011.

[3] T. Sui, "Progress and future perspectives of CSA cements in China," in International Workshop on Calcium Sulfoaluminate cements, Murten, Switzerland, 2018.

[4] E. M. Gartner and D. E. Macphee, "A physico-chemical basis for novel cementitious binders," Cement and Concrete Research, vol. 41, no. 7, pp. 736-749, Jul. 2011.

[5] E. Gartner and H. Hirao, "A review of alternative approaches to the reduction of $\mathrm{CO} 2$ emissions associated with the manufacture of the binder phase in concrete," Cement and Concrete Research, vol. 78, pp. 126-142, Dec. 2015.

[6] W. Dienemann, D. Schmitt, F. Bullerjahn, and M. B. Haha, "Belite-Calciumsulfoaluminate-Ternesite (BCT)-a new low carbon clinker technology," Cement International, vol. 11, no. 4, pp. 100-109, 2013.

[7] J. Skocek, M. Zajac, B. Bullerjahn, and M. Ben Haha, "Effect of retarders on the early performance of CSA-type cement," 19th Ibausil. Weimar, Germany, 2015.

[8] M. Zajac, J. Skocek, C. Stabler, F. Bullerjahn, and M. Ben Haha, "Hydration and performance evolution of belite-ye'elimite-ferrite cement," Advances in Cement Research, pp. 1-14, Sep. 2018.

[9] F. Bullerjahn, E. Boehm-Courjault, M. Zajac, M. Ben Haha, and K. Scrivener, "Hydration reactions and stages of clinker composed mainly of stoichiometric ye'elimite," Cement and Concrete Research, vol. 116, pp. 120-133, Feb. 2019.

[10] F. Bullerjahn, M. Zajac, M. Ben Haha, and K. L. Scrivener, "Factors influencing the hydration kinetics of ye'elimite; effect of mayenite," Cement and Concrete Research, vol. 116, pp. 113-119, Feb. 2019.

[11] F. Winnefeld and B. Lothenbach, "Phase equilibria in the system Ca 4 Al 6012 SO 4-Ca 2 SiO 4-CaSO 4-H 2 O referring to the hydration of calcium sulfoaluminate cements," RILEM Technical Letters, vol. 1, pp. 10-16, 2016. 
[12] S. Berger, C. Cau Dit Coumes, P. Le Bescop, and D. Damidot, "Hydration of calcium sulfoaluminate cement by a $\mathrm{ZnCl} 2$ solution: Investigation at early age," Cement and Concrete Research, vol. 39, no. 12, pp. 1180-1187, Dec. 2009.

[13] S. Berger, C. C. D. Coumes, P. Le Bescop, and D. Damidot, "Influence of a thermal cycle at early age on the hydration of calcium sulphoaluminate cements with variable gypsum contents," Cement and Concrete Research, vol. 41, no. 2, pp. 149-160, Feb. 2011.

[14] P. Wang, N. Li, and L. Xu, "Hydration evolution and compressive strength of calcium sulphoaluminate cement constantly cured over the temperature range of 0 to $80{ }^{\circ} \mathrm{C}$," Cement and Concrete Research, vol. 100, pp. 203-213, Oct. 2017.

[15] D. Gastaldi et al., "Hydration products in sulfoaluminate cements: Evaluation of amorphous phases by XRD/solid-state NMR," Cement and Concrete Research, vol. 90, pp. 162-173, Dec. 2016.

[16] F. Song, Z. Yu, F. Yang, Y. Lu, and Y. Liu, "Microstructure of amorphous aluminum hydroxide in belitecalcium sulfoaluminate cement," Cement and Concrete Research, vol. 71, pp. 1-6, May 2015.

[17] Y. Zhang and J. Chang, "Microstructural evolution of aluminum hydroxide gel during the hydration of calcium sulfoaluminate under different alkali concentrations," Construction and Building Materials, vol. 180, pp. 655-664, Aug. 2018.

[18] B. Lothenbach, L. Pelletier-Chaignat, and F. Winnefeld, "Stability in the system CaO-Al2O3-H2O," Cement and Concrete Research, vol. 42, no. 12, pp. 1621-1634, Dec. 2012.

[19] D. Jansen, A. Spies, J. Neubauer, D. Ectors, and F. Goetz-Neunhoeffer, "Studies on the early hydration of two modifications of ye'elimite with gypsum," Cement and Concrete Research, vol. 91, pp. 106-116, 2017.

[20] M. Zajac, J. Skocek, F. Bullerjahn, and M. Ben Haha, "Effect of retarders on the early hydration of calcium-sulpho-aluminate (CSA) type cements," Cement and Concrete Research, vol. 84, pp. 62-75, Jun. 2016.

[21] V. Morin, P. Termkhajornkit, B. Huet, and G. Pham, "Impact of quantity of anhydrite, water to binder ratio, fineness on kinetics and phase assemblage of belite-ye'elimite-ferrite cement," Cement and Concrete Research, vol. 99, pp. 8-17, Sep. 2017.

[22] L. Zhang and F. P. Glasser, "Hydration of calcium sulfoaluminate cement at less than 24 h," Advances in Cement Research, Oct. 2002.

[23] J.-B. Champenois et al., "Influence of sodium borate on the early age hydration of calcium sulfoaluminate cement," Cement and Concrete Research, vol. 70, pp. 83-93, Apr. 2015.

[24] C. Cau Dit Coumes, M. Dhoury, J.-B. Champenois, C. Mercier, and D. Damidot, "Combined effects of lithium and borate ions on the hydration of calcium sulfoaluminate cement," Cement and Concrete Research, vol. 97, pp. 50-60, Jul. 2017.

[25] F. Winnefeld and B. Lothenbach, "Hydration of calcium sulfoaluminate cements - Experimental findings and thermodynamic modelling," Cement and Concrete Research, vol. 40, no. 8, pp. 1239-1247, Aug. 2010.

[26] J. Wang, I. Baco, V. Morin, G. Walenta, D. Damidot, and E. Gartner, "Hydration mechanism of cements based on low-CO2 clinkers containing belite,ye_elimite and calcium.pdf," in 2010, At Jinan, China, 2010, vol. Session 1.

[27] F. Bullerjahn, "Characterisation and hydration of ye' elimite containing cements," EPFL, 2018.

[28] K. L. Scrivener and A. Nonat, "Hydration of cementitious materials, present and future," Cement and concrete research, vol. 41, no. 7, pp. 651-665, 2011.

[29] D. Damidot, B. Lothenbach, D. Herfort, and F. P. Glasser, "Thermodynamics and cement science," Cement and Concrete Research, vol. 41, no. 7, pp. 679-695, Jul. 2011.

[30] D. Damidot and F. P. Glasser, "Thermodynamic investigation of the CaO-Al2O3-CaSO4-K2O-H2O system at $25^{\circ} \mathrm{C}$," Cement and concrete research, vol. 23, no. 5, pp. 1195-1204, 1993.

[31] D. Damidot and F. P. Glasser, "Thermodynamic investigation of the CaO-Al2O3-CaSO4-H2O system at $25^{\circ} \mathrm{C}$ and the influence of Na2O," Cement and Concrete Research, vol. 23, no. 1, pp. 221-238, 1993.

[32] D. Damidot and F. Glasser, "Investigation of the CaO-Al2O3-SiO2-H2O system at 25 C by thermodynamic calculations," Cement and Concrete Research, vol. 25, no. 1, pp. 22-28, 1995. 
[33] W. Hummel, U. Berner, E. Curti, F. Pearson, and T. Thoenen, "Nagra/PSI chemical thermodynamic data base 01/01," Radiochimica Acta, vol. 90, no. 9-11/2002, pp. 805-813, 2002.

[34] W. Hummel, U. Berner, E. Curti, F. Pearson, and T. Thoenen, "Nagra Technical Report NTB 02-16," Wettingen, Switzerland, 2002.

[35] T. Matschei, B. Lothenbach, and F. P. Glasser, "Thermodynamic properties of Portland cement hydrates in the system $\mathrm{CaO}-\mathrm{Al} 2 \mathrm{O} 3-\mathrm{SiO} 2-\mathrm{CaSO} 4-\mathrm{CaCO} 3-\mathrm{H} 2 \mathrm{O}$," Cement and Concrete Research, vol. 37, no. 10, pp. 1379-1410, Oct. 2007.

[36] B. Lothenbach et al., "Cemdata18: A thermodynamic database for hydrated Portland cements and alkali-activated materials," Cement and Concrete Research, in press 2018.

[37] D. A. Kulik et al., "GEM-Selektor geochemical modeling package: revised algorithm and GEMS3K numerical kernel for coupled simulation codes," Computational Geosciences, vol. 17, no. 1, pp. 1-24, 2013.

[38] T. Wagner, D. A. Kulik, F. F. Hingerl, and S. V. Dmytrieva, "GEM-Selektor geochemical modeling package: TSolMod library and data interface for multicomponent phase models," The Canadian Mineralogist, vol. 50, no. 5, pp. 1173-1195, 2012.

[39] W. Wang, X. Chen, Y. Chen, Y. Dong, and C. Ma, "Calculation and verification for the thermodynamic data of 3CaO. 3Al2O3. CaSO4," Chinese Journal of Chemical Engineering, vol. 19, no. 3, pp. 489-495, 2011.

[40] J. Wang, "Le mécanisme d'hydratation de ciment basé aux mâchefers Bas-CO2 contenant belite, ye'elimite et l'alumino-ferrite de calcium," Université des Sciences et Technologie de Lille-Lille I, 2010.

[41] P. Barret, D. Bertrandie, and D. Beau, "Calcium hydrocarboaluminate, carbonate, alumina gel and hydrated aluminates solubility diagram calculated in equilibrium with $\mathrm{CO} 2 \mathrm{~g}$ and with $\mathrm{Naaq}+$ ions," Cement and concrete research, vol. 13, no. 6, pp. 789-800, 1983.

[42] F. M. Lea and P. C. Hewlett, Lea's chemistry of cement and concrete. Elsevier, 2004.

[43] G. Le Saout, "Calcium aluminate based hydraulic binders: a review," in Conference: 2nd International conference on the chemistry of construction materials, Munisch, Germany, 2016, vol. 50.

[44] L. H. J. Martin, F. Winnefeld, E. Tschopp, C. J. Müller, and B. Lothenbach, "Influence of fly ash on the hydration of calcium sulfoaluminate cement," Cement and Concrete Research, vol. 95, pp. 152-163, May 2017.

[45] M. C. Martín-Sedeño et al., "Aluminum-rich belite sulfoaluminate cements: Clinkering and early age hydration," Cement and Concrete Research, vol. 40, no. 3, pp. 359-369, Mar. 2010.

[46] F. Bullerjahn, D. Schmitt, and M. Ben Haha, "Effect of raw mix design and of clinkering process on the formation and mineralogical composition of (ternesite) belite calcium sulphoaluminate ferrite clinker," Cement and Concrete Research, vol. 59, pp. 87-95, May 2014. 